\title{
Authors' Reply: Honorary Authorships in Surgical Literature
}

\author{
Jacky D. Luiten ${ }^{1}$ (1) P Pravesh S. Gadjradj ${ }^{2}$
}

Published online: 11 November 2019

(C) Société Internationale de Chirurgie 2019

We would like to thank Dr. Tarpley for her interest in our study and for allowing us to discuss our findings [1].

Even though we agree that the International Committee of Medical Journal Editor (ICMJE) guidelines can be somewhat ambiguous when applied, we do think that these guidelines can also be applied for low- and middle-income countries [2].

The ICMJE guidelines are intentioned to give researchers a tool to maintain their integrity and to prevent honorary authorship from happening. Take for example the pressure junior researchers can feel when they need to include a senior member of their research group who hasn't contributed to the study. Another example of honorary authorship was published in Nature. In 2018, Nature published a news article in which the Korean government identified 82 academic papers on which authors had named their children or relatives as author [3]. Motivation may lay in increased chances at university. Further research showed that in 39 of the papers, students seem to have participated in the research.

If researchers would have to take into account all contributions essential for success, then where does this stop? Patients are priceless for all research, original research is priceless for conducting a systematic review or metaanalysis, and validated patient-reported outcome measures are priceless for conducting patient-involved research. This doesn't mean that patients, authors of original articles, or authors who validated the patient-reported outcome

Jacky D. Luiten

jd.luiten@etz.nl

1 Department of Surgery, Elisabeth-Tweesteden Hospital, Hilvarenbeekseweg 60, 5022 GC Tilburg, The Netherlands

2 Department of Neurosurgery, Leiden University Medical Center, Leiden, The Netherlands measures used should be enlisted as co-author or should be acknowledged in the acknowledgements section.

The concerns expressed by Dr. Tarpley, who states that acknowledgement is not an adequate compensation for efforts in low- and middle-income countries when only tasks are performed which rule out authorship, are addressed. In order to fulfill the authorship criteria, researchers from low- and middle-income countries should have the opportunity to revise the manuscript and to approve the final version, because only then, these researchers from low- and middle-income countries can be accountable for the research published.

We would like to conclude our reply by emphasizing that the ICMJE criteria for authorship are meant as a guideline and not a rule and therefore sometimes an exception can be made. This exception is made after critically evaluating every authorship, which is the main message of our manuscript.

\section{References}

1. Luiten JD, Verhemel A, Dahi Y et al (2019) Honorary authorships in surgical literature. World J Surg 43:696-703. https://doi.org/10. 1007/s00268-018-4831-3

2. Defining the Role of Authors and Contributors: International Committee of Medical Journal Editors (2017). http://www.icmje. org/recommendations/browse/roles-and-responsibilities/definingtherole-of-authors-and-contributors.html. Accessed 25 Oct 2019

3. Zastrow M (2018) Child authors spark probe. Nature 554:154-155

Publisher's Note Springer Nature remains neutral with regard to jurisdictional claims in published maps and institutional affiliations. 